\title{
HVMANITAS
}

\section{As igrejas de Lalibela na versão alemã da Verdadera Informaçam}

Autor(es): $\quad$ Carreira, José Nunes

Publicado por: Faculdade de Letras da Universidade de Coimbra, Instituto de Estudos

URL

persistente: URI:http://hdl.handle.net/10316.2/8521

DOI: $\quad$ DOI:http://dx.doi.org/10.14195/2183-1718_62_10

Accessed : $\quad$ 26-Apr-2023 15:31:52

A navegação consulta e descarregamento dos títulos inseridos nas Bibliotecas Digitais UC Digitalis, UC Pombalina e UC Impactum, pressupõem a aceitação plena e sem reservas dos Termos e Condições de Uso destas Bibliotecas Digitais, disponíveis em https://digitalis.uc.pt/pt-pt/termos.

Conforme exposto nos referidos Termos e Condições de Uso, o descarregamento de títulos de acesso restrito requer uma licença válida de autorização devendo o utilizador aceder ao(s) documento(s) a partir de um endereço de IP da instituição detentora da supramencionada licença.

Ao utilizador é apenas permitido o descarregamento para uso pessoal, pelo que o emprego do(s) título(s) descarregado(s) para outro fim, designadamente comercial, carece de autorização do respetivo autor ou editor da obra.

Na medida em que todas as obras da UC Digitalis se encontram protegidas pelo Código do Direito de Autor e Direitos Conexos e demais legislação aplicável, toda a cópia, parcial ou total, deste documento, nos casos em que é legalmente admitida, deverá conter ou fazer-se acompanhar por este aviso.

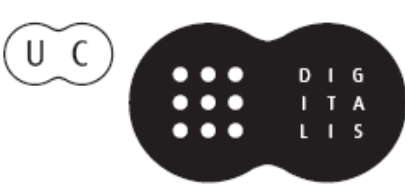


humanitas

Vol. LXII

2010 


\title{
AS IGREJAS DE LALIBELA NA VERSÃO ALEMÃ DA VERDADERA INFORMAÇAM
}

\author{
José Nunes Carreira \\ Universidade de Lisboa
}

\section{Resumo}

A tradução alemã da Verdadera informaçam (1566) depende confessadamente de uma tríplice Vorlage: original português de 1540, versão italiana de Ramusio (1550) e manuscrito de Damião de Góis. A versão italiana era notoriamente mais curta que a edição de Lisboa. Ao invés, o tradutor alemão notou grandes lacunas no original português e procurou melhorar o texto com base no manuscrito. É o que acontece na descrição das igrejas de Lalibela. As plantas das igrejas são uma novidade absoluta da edição germânica.

Palavras-chave: igreja, planta, texto, tradução.

\begin{abstract}
The German translation of father Francisco Álvares' Verdadera informaçam (1566) depends admittedly on a threefold Vorlage: the Portuguese original (1540), the Italian translation by Ramusio (1550) and a manuscript of Damião de Góis. The Italian translation was notoriously shorter than the Lisbon edition. On the contrary, the German translator noticed large lacunae in the Portuguese original and tried to get the text better on the base of the manuscript. It is the case in the description of the churches in Lalibela. The plans of the churches are absolutely new in the German translation.
\end{abstract}

Key-words: church, plan, text, translation. 
Publicada em Lisboa em 1540, a «Verdadera informaçam das terras do Preste Joam, segundo vio e escreveo ho padre Francisco Alvarez capellã del Rey nosso senhor» ${ }^{1}$, avivou pela Europa fora a curiosidade sobre a Abissínia e o seu peculiar monarca. Bastou uma década para ser traduzida em italiano ${ }^{2}$, e logo depois em espanhol ${ }^{3}$ e francês ${ }^{4}$. Em 1566 saía dos prelos de Joachim Heller em Eissleben o "Wahrhaftiger Bericht von den Landen / auch Geistlichem und Weltlichem Regiment / des Mechtigen Königs in Ethiopien / den wir Priester Johan nennen / wie solches durch die Kron Portugal mit besondern vleiss erkundiget worden / beschrieben durch Herrn Franciscum Alvares / soderhalben sechs Jahr lang an / gedachtts Priester Johans Hoffe verharren müssen / Aus der Portugallischen und Italienischen sprach in das Deutsche gebracht". O relato do Padre Francisco Álvares sobre a embaixada portuguesa à corte do Preste João das Índias galgava mais uma barreira linguística. Com ele tem início uma série de relatos de viajantes portugueses, na sua maior parte missionários, «que nos princípios do século XVII trazem... um contributo fundamental para o conhecimento

1 Agora novamente impresso por mandado do dito senhor em casa de Luis Rodriguez livreiro de sua alteza, Lisboa 1540.

2 Viaggio nella Ethiopia al Prete Ianni fatto per Don francesco Alvarez Portoghese, em G.-B. Ramusio, Delle Navigationi et Viaggi, I, Venetia 1563, fl. 189v. ss. A primeira edição dos Viaggi, I, é de 1550, dedicado à África. O segundo volume (Ásia) apareceria em 1559; seis anos depois do terceiro (1553), sobre a América. Giovanni Battista Ramusio foi um notável humanista, historiador e geógrafo do Renascimento italiano. Nascido em Treviso (20/07/1485), tornar-se-ia chanceler (1513) e depois secretário (1515) do Senado de Veneza, vindo a morrer em Pádua (10/07/1557). Cf. R. Almagià, «Ramusio, Giovanni Battista», Enciclopedia Italiana, XXVIII, Roma 1935, 820.

3 Historia de las cosas de Ethiopia, en la qual se cuenta muy copiosamente, el estado y potencia del Emperador della (que es el que muchos han pensado ser el Preste Juan) con otras infinitas particularidades, assi de la religion de aquella gente, como de sus cerimonias. Segun que de todo ello fue testigo de vista Francisco Alvarez Capellan del Rey Don Manuel de Portugal, Amberes 1557, Toledo 1558, Saragoza 1561.

4 Historiale description de l'Ethiopie contenant vraye relation des terres et pays $d u$ grand Roy et Empereur Prete-Jean. Traduit de Francisco Alvares par Jean Bellere, Anvers 1558. No mesmo ano e na mesma cidade, outra edição, chez Christophe Plantin. A partir da versão italiana de G.-B. Ramusio, apareceu novamente uma Histoire de l'Ethiopie décrite par Dom Francisque Alvarez, en son voyage fait esdites parties (tradução de Jean Temporale), tomo III de De l'Afrique, contenant la description de ce pays, faite par Léon l'African et la navigation des anciens capitaines portugais aux Indes orientales et occidentales, Paris 1830. 
geográfico da região». ${ }^{5}$ A Verdadera Informaçam tornou-se no grande ponto de encontro da Europa culta com o país do lendário príncipe cristão do interior da África. ${ }^{6}$

O capelão da embaixada de D. Rodrigo de Lima ficou vivamente impressionado com o conjunto monumental atribuído a Lalibela. O título do capítulo LIV já insinua a grandeza: «Dos grandes edifícios de igrejas que há na terra de Abugima que fez Lalibela Rei e da sepultura sua na igreja de Gólgota.» E o relato que logo enceta é bem explícito: «Uma jornada desta igreja de Imbra Cristo estão edifícios os quais me parecem que no mundo se possam achar outros tais e tantos, e são de igrejas todas cavadas em pedras mui bem lavradas e os nomes destas igrejas são estes: Emanuel, Salvador, Santa Maria, Santa Cruz, São Jorge, Gólgota, Belém, Marmóreos, os Mártires.» ${ }^{7}$

O espanto foi visível: «Estas cousas me amostravam como que me espantaria eu de as ver.» ${ }^{8}$ A maravilha era de tal monta que o autor teve de jurar por «Deus em cujo poder estou que todo o escrito é verdade e é muito mais do que escrevi e o deixei por não me tacharem de mentira». Reconhece que «a estas obras não foi outro português senão eu que lá fui duas vezes, pelo que ouvia delas». ${ }^{9}$

Não era para menos. São onze igrejas talhadas cada uma num único bloco de pedra sobre um monte denominado Calvário, a dois mil e setecentos metros de altitude, no norte da Etiópia. Estudos recentes estimam que devem ter sido removidos a escopro perto de cem mil metros cúbicos de rocha. Os templos estão ligados entre si por corredores e escadarias subterrâneas. Mas cada um é uma criação distinta, onde tudo foi talhado na rocha. Tal como referiu o capelão feito cronista, o impressionante monumento seria

5 S. Moscati, Las antiguas civilizaciones semíticas, trad., Barcelona 1960, pp. 254-255.

6 Cf. A. A. Banha de Andrade, «Francisco Alvares e o êxito europeu da Verdadeira Informação sobre a Etiópia», in Presença de Portugal no mundo. Actas do Colóquio, Academia Portuguesa da História, Lisboa 1982, pp. 285-339.

7 P. Francisco Álvares, Verdadeira informação das terras do Preste João das Índias, Lisboa 1954 (reprodução fac-similada da edição de 1943), LIV, 132.

8 Ibid., LIV, 133.

9 Ibid., LV, 139. 
obra de Lalibela (1172-1212). ${ }^{10}$ A lenda viu aí a mão de artistas celestiais. Francisco Álvares diz apenas que foi obra de «brancos», chamados «gibetas», uma vez que os abexins reconheciam «não saberem fazer cousa nenhuma bem feita». ${ }^{11}$ No que tem parcialmente o acordo de muitos arqueólogos, segundo os quais os artífices locais podem ter sido ajudados por canteiros e escultores de outra proveniência, nomeadamente de Alexandria. Mas o estilo das igrejas é caracteristicamente etíope. ${ }^{12}$

Ressalta a admiração do cronista pelo árduo trabalho de afeiçoar a rocha: «toda cavada na mesma pedra» (Gólgota) ${ }^{13}$, «só em uma rocha talhada» (São Salvador) ${ }^{14}$, «tudo é do mesmo rochedo» (capela-mor de São Salvador, com sua charola $)^{15}$, «não há em toda esta roca em que está a igreja uma só diferença, toda parece um só mármore» (São Salvador) ${ }^{16}$, «tudo roca talhada e mui brava» (Nossa Senhora) ${ }^{17}$, «toda da mesma roca sem peça nem talha» (Emanuel) $)^{18}$, «tudo é roca brava sem ter mais de uma entrada» (São Jorge) ${ }^{19}$ A igreja do Gólgota e respectivas capelas «têm seus altares e charolas com seus esteios da mesma pedra» e «uma sepultura entalhada na mesma pedra da igreja que dizem que é feita à feição da sepultura de Cristo em Jerusalém»; no seu circuito, «tudo (é) artificialmente cavado ou picado que aí não há que cavar, porque a pedra é dura e de grandes muros como o Porto em Portugal». ${ }^{20}$

E não foi só talhar rocha tosca em paredes, frestas e esteios. Havia trabalho delicado de escultor em arcos e abóbadas, tão gentis que pareciam

10 O antropónimo sobreviveu como nome da pequena cidade, que vive essencialmente do comércio e do turismo. O conjunto monumental foi objectos de escavações nas décadas de 20 e 30 do século passado, mas só a partir dos anos sessenta teve início um sério trabalho de restauro.

11 P. Francisco Álvares, Verdadeira informação, LV, 140.

12 Cf. P. dos Reis Filipe, «A Abissínia de Francisco Álvares», J. Augusto Ramos et alii (ed.), Percursos do Oriente Antigo. Homenagem a José Nunes Carreira, Instituto Oriental, Lisboa 2004, pp. 196-187. Todo o artigo pp. 179-194.

13 P. Francisco Álvares, Verdadeira informação, LIV, 132.

14 Ibid., LV, 134.

15 Ibid., 135.

16 Ibidem.

17 Ibid., 137.

18 Ibid., 138. «Tem a igreja todo seu circuito como muro talhado de dentro e de fora da mesma roca...» (ibidem).

19 Ibid., 139.

20 Ibid., LIV, 134. 
saídos de mãos de ourives: uma pequena igreja «mui bem lavrada, de muita gentileza» ${ }^{21}$; «toda a laçaria que dizer se possa, que ourives em prata, nem cireiro em cera não podiam fazer mais obra» ${ }^{22}$; «abóbadas em grande maneira bem talhadas» e «grandes laçarias, como espelhos ou fechos ou rosas que põem nas abóbadas em que fazem rosas e outras obras gentis» ${ }^{23}$; uma «abóbada em tal maneira lavrada que sendo obra de peças e pedra mole que mais direita nem melhor lavrada, nem de mais lavores se não possa fazer» ${ }^{24}$; «grandes laços e rosas na mesma roca lavradas muito subtilmente», «cercos e abóbadas mui revindas e mui bem feitas», «uma charola que parece em sua laçaria que foi imprimida em cera» 25 ; «duas frestas mui bem obradas» ${ }^{26}$, uma parede exterior composta de «fiadas de paredes, e uma sai para fora e outra entra para dentro dois dedos. E outra torna a sair e outra a entrar... e a fiada da pedra que sai é de dois palmos de largo e a que entra é de um». ${ }^{27}$

A descrição está longe de ser bem organizada e não segue a ordem por que as igrejas foram mencionadas em bloco. A igreja do Gólgota toma a dianteira, ocupando praticamente todo um capítulo. Dadas as dimensões (120x72 palmos), descreve-se o corpo da igreja: «Está o céu desta igreja sobre cinco esteios, dois por banda e um no meio como em quinas e o céu ou tecto todo é chão como o andar da igreja e das bandas em grande maneira lavradas, assim frestas como portas...». Intercalada a notícia da sepultura («da maneira que a de Santiago de Galiza, que é em Compostela»), volta-se à descrição da igreja: «Em o meio do corpo da igreja está o sinal de uma porta como porta de alçapão, está tapada com um grande pedra, como pedra de altar, muito justa na dita porta. Dizem que aquela é a entrada da casa de baixo e que ninguém entra dentro, nem parece que aquela pedra ou porta se possa tirar.» «Para a outra parte da igreja estão duas imagens grandes entalhadas na mesma parede que ficam quase apartadas dela. (...) É uma das imagens de São Pedro e outra de São João...» À volta da igreja há um «andaimo... como crasta e mais baixo que o corpo da igreja e desce homem da igreja para este andaimo estão três frestas por banda, seja naquela altura

\footnotetext{
21 Ibid., 133 (igreja anexa a Gólgota).

22 Ibid., 132 (Gólgota).

23 Ibid., LV, 134-135 (São Salvador).

24 Ibid., 135 (São Salvador).

25 Ibid., 136 (Nossa Senhora)

26 Ibid., 137 (Santa Cruz).

27 Ibid., 138 (Emanuel).
} 
que a igreja é mais alta que o andaimo». «A entrada deste circuito é por baixo da roca em grande altura e comprido de treze palmos». ${ }^{28}$

Descrito o corpo principal da igreja, acresce referir a presença de duas capelas - uma mais vasta e quadrada ( 52 x 52 palmos), outra tão pequena que dispensa medidas:

«Tem mais esta igreja uma capela sobre si quase igreja, esta é de naves sobre seis esteios, seja, três por banda. Esta é mui bem lavrada, de muita gentileza e a nave do meio bem erguida e enarcada e suas festas e portais bem lavrados, seja, porta principal e uma travessa, que a outra serve para a igreja grande. Esta capela é tanto de ancho como de longo, seja cinquenta e dois palmos de ancho e outros tantos de comprido. Outra capela tem, muito alta e pequena, como coruchéu com muitas frestas na mesma altura». ${ }^{29}$

Enigmático é «o andaimo que é derredor da igreja» e ao mesmo tempo «como crasta e mais baixo que o corpo da igreja», com «três frestas por banda». O editor moderno entendeu o «andaimo» como «galeria alta e exterior» ${ }^{30} \mathrm{O}$ que não se coaduna com o teor do texto: o andaimo está num piso inferior, pois para aí «desce homem da igreja»; é «cavado por baixo em tanta altura e fundo, quanto é o andar da igreja acima». «E olhando homem de cada dia destas frestas que é contra o sol, vê estar a sepultura no direito do altar-mor.» Estranha maneira de apresentar a cripta, destinada a albergar o túmulo do rei! Como pode estar o andaimo «derredor da igreja», se o túmulo se localiza debaixo do altar-mor?

Feita a partir de uma tríplice Vorlage, não se espera que a versão alemã reproduza literalmente o original português. Nas igrejas de Lalibela como que levanta o véu sobre enigma, até para quem criou a lenda dos anjos canteiros, que era a quantidade de trabalho em pedra dura. O tradutor suavizou a dificuldade, introduzindo «em pedra macia»: as «igrejas todas cavadas em pedras mui bem lavradas» deram em alemão «Kirchen in lebendigen Fels / in einen zarten taubenstein / sehr artlich unnd künstlich gehawen». ${ }^{31}$ Verdade seja que a versão apenas generalizou o que lia no

28 Ibid., LIV, 132-133.
29 Ibid., 133-134.
30 Ibid., 132, n. 3.
31 P. Francisco Álvares, Wahrhaftiger Bericht, 169 (196); sublinhado meu. Nem com recurso a uma germanista profissional consegui identificar o tipo de pedra «taubenstein». 
original português sobre uma abóbada de São Salvador: «sendo obra de peças e pedra mole». ${ }^{32}$

E parece resolver o enigma do «andaimo» do Gólgota: havia sob a igreja «outra igreja da mesma figura cavada em rocha viva tão grande como o chão da de cima e de cerca de uma lança de altura, aí está o túmulo do rei directamente debaixo do altar-mor». ${ }^{33}$ Mais abaixo é que refere o circuito: «À volta da igreja há um grande espaço, como crasta, mas sob a igreja em frente para Oriente tem cinco degraus bem para baixo três frestas que dão luz na igreja inferior, de baixo até ao pavimento da igreja, que está tão alto na outra terra como fundo descem os cinco degraus para baixo da terra; pelas mesmas frestas vêem o supra referido túmulo, que está directamente sob o altar-mor.» ${ }^{34}$

A elaboração final do escrito do Padre Francisco Álvares concentrou duas descrições num só texto - a do circuito que parecia um claustro e a da igreja inferior ou cripta. Em termos técnicos, é uma lectio conflata.

Não é de monta a divergência no nome do autor do conjunto monumental: Lulibella, em vez de Lalibela. Mas outras leituras dão nas vistas. Falta a indicação da largura da igreja: 72 palmos; em contrapartida, diz-se que o comprimento é de «120 palmos ou pés» («hundert und zwanzig Palmen oder schuen lang»), como se as duas medidas fossem iguais (palmo = 22,5 cm; pé cerca de 30,5 cm); «com toda a laçaria que dizer se possa» traduziu-se num bastante genérico «trabalhado com subtileza e arte» («subtil und künstlich ausgearbeitet»). Já «as duas imagens grandes (de São Pedro e São João) entalhadas na mesma parede» deram-se como «tão artisticamente modeladas como se vivessem» («also so künstlich geformiret / als sie lebten»).

32 P. Francisco Álvares, Verdadeira informação, LIV, 135

33 P. Francisco Álvares, Wahrhafter Bericht, 169 (de facto, 196): «Unter dieser Kirchen hat es noch ein ander Kirchen gleicher gestalt in lebendigen stein ausgehauen / eben so gros wie der boden von der obern ist / und ungefehrlich eines Spies hoch / da ist des Königes Grab stracks unter dem hohen Altar.»

34 Ibid., 196 (169!)-197: «Umb die Kirchen hat es ein grossen raum wie ein Kloster / aber unter der Kirchen vorn gegen Orient hat es fünff staffeln tieff hinab drey Fenster / die geben liecht in der untern Kirchen / von unten auff bis an der obern Kirchen boden / der stehet eben so hoch ob der andern erde / als tieff die fünff staffel unter die erde gehn / durch dieselben Fenster / sihet man die obermelte begrebnus/ welche stracks unter dem hohem Altar stehet.» 
O tradutor viu-se em palpos de aranha para verter «uma porta como porta de alçapão»: «um grande buraco pelo qual se pode ir à igreja de baixo ou cripta» («ein gros loch / dadurch man in die unter Kirchen oder Krufft komen kan»). Mas não servia para o fim a que se destinava: estava tapado «com uma grande pedra, como pedra de altar», na versão «com uma pedra larga, como se fosse laje de sepulcro» («dasselbe ist mit einem breiten stein / gleich als ob es ein grabstein were bedeckt»). $\mathrm{O}$ «nem parece que aquela pedra ou porta se possa tirar» recebeu um toque mais pessoal: «mas quis-me parecer que ninguém por aí desce, em virtude de ninguém poder tirar facilmente a pedra» («aber wie ich mich bedüncken lies / so komet niemand hinab /aus ursachen das man den stein nicht leichtlich auffheben kan»).

Localizaram-se as capelas: a grande, «ao lado desta igreja à mão esquerda» («neben dieser Kirchen auff die lincken hand»); a «outra capela... muito alta e pequena» «à mão direita da igreja grande» («auff die rechte hand der grossen Kirchen») e comparada a torre sineira («wie spitzen von einem glockenthurn»). As dimensões da capela é que devem estar mais correctas no alemão do que no português: 36 palmos de altura e 12 de largo ${ }^{35}$ (P: «tanto de ancho como de longo, seja doze palmos). Não é possível imaginar «muitas frestas» quadradas, de 2,70 m de lado, num edifício pequeno e cavado na rocha.

A planta acrescentada em Eissleben ${ }^{36}$, com a respectiva legenda na $p$. 200, reproduz a descrição de Francisco Álvares com bastante pormenor, salvo a localização das capelas (no texto coloca-se a grande à esquerda e a pequena à direita).

A - Capela-mor («capela maior») com altar.

B - Alçapão.

$\mathrm{C}-$ «Cinco esteios, dois por banda e um no meio»

$\mathrm{D}-$ - «éu ou tecto».

E - Abóbada central ou abóbada com um pilar (P 132: um esteio «no meio»).

F - Porta principal (P 133: «porta principal» per transenam).

$\mathrm{G}-$ Circuito à volta da igreja (P 133: «andaimo»)

$\mathrm{H}$ - Janelas (P 132: «três frestas por banda»).

$\mathrm{K}$ - Porta lateral da igreja.

L - Capela em lugar da torre sineira (P 133-134: «Outra capela ... muito alta e pequena... com muitas frestas na mesma altura»).

$\mathrm{M}$ - As «imagens entalhadas na pedra» (P 133).

$\mathrm{N}$ - Entrada sob a rocha para o mosteiro.

$\mathrm{O}$ - Medida do palmo.

$\mathrm{P}$ - Montanha e rocha circundante.

35 Ibidem.

36 Ver gravura p. 173. 


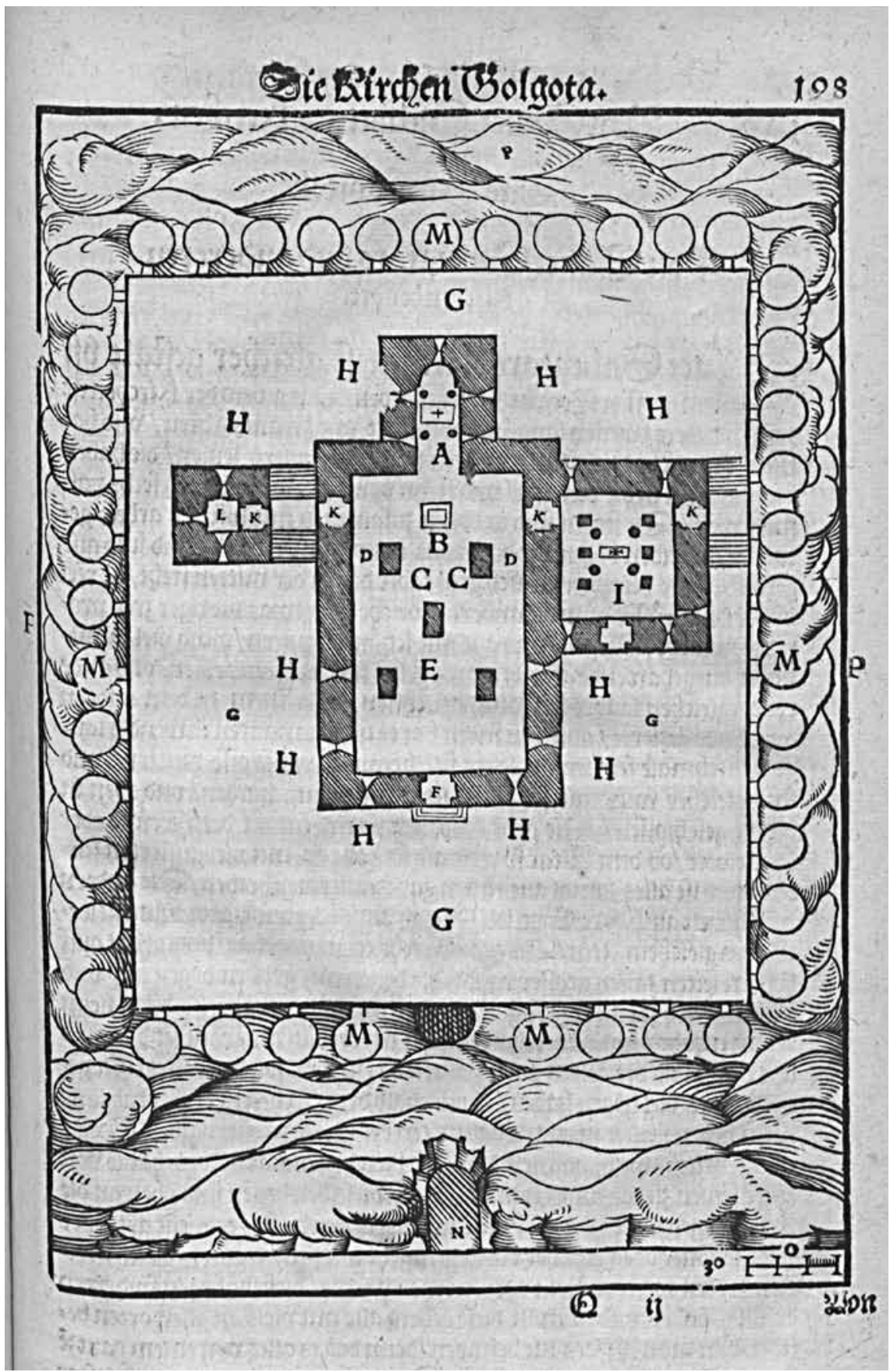


A planta visualiza todos os elementos essenciais da descrição, colocando as capelas uma de cada lado e interpretando a «capela... muito alta e pequena» como substituto da torre sineira. É uma ajuda preciosa à descrição do cronista. Estranha é a posição da porta principal da capela quadrada - em oposição à porta travessa que dá para a igreja e não ao centro do eixo vertical. A capela pequena (L) tem a sua porta, com acesso a partir de um corredor vindo de outra porta travessa da igreja. Nem falta a medida do palmo.

A descrição da igreja seguinte no original português não prima pela clareza: «A igreja de São Salvador está em uma roca talhada, é muito grande, tem no vão em comprido duzentos palmos e de largo cento e vinte. Tem cinco naves, em cada uma sete colunas de quadra, a grande quatro palmos e outro tanto têm as paredes da igreja. As colunas muito bem lavradas e arcos que descem, quantidade e de grossura, de um palmo no baixo da abóbada e as abóbadas em grande maneira bem lavradas e de grande altura, principalmente a do meio que é muito alta e as outras ao longo chegadas e está esta em formosa altura e os mais dos cabos mais baixos, todos em seu compasso. Na principal altura destas naves há grandes laçarias, como espelhos ou fechos ou rosas que põem nas abóbadas em que fazem rosas e outras obras gentis. Tem pelas bandas mui formosas frestas e de grandes laçarias compridas e estreitas no meio e para dentro e fora largas como frecheiros de muros, estreitas de fora e largas de dentro. (...) A capela-mor é muito alta e mui alta a charola sobre o altar com um esteio em cada quadra. Tudo é do mesmo penedo e a todas as outras não vestem suas capelas e altares com suas charolas, como a capela-mor em suas grandezas. A porta principal tem de cada cabo muitos e grandes botaréus e começa a porta em mui grandes arcos e vem apertando, em feição de outros arcos, até que vem em pequena porta que não é mais de nove palmos em alto e quatro e meio de largo. Desta maneira são as portas travessas, senão que não começam em tanta largueza e acabam na largueza da porta principal.» ${ }^{37}$

Não se entende como se salienta das sete colunas uma «grande de quatro palmos». Como assim? Não têm de ser as colunas de uma abóbada todas de igual tamanho? O texto alemão omite o número sete. Fala apenas em «colunas», que «têm quatro palmos no quadrado e estão a seis

37 P. Francisco Álvares, Verdadeira informação, LV, 134-135. 
palmos das paredes». ${ }^{38}$ Mas a planta traz três renques de sete colunas cada um.

O arranjo exterior do templo não foi descurado, nem na arquitectura nem na sua descrição: «Da parte de fora desta igreja estão sete esteios com lunas as quais estão afastadas da parede da igreja doze palmos e, de esteio a esteio, um arco e, de cima da igreja para estes arcos, abóbada em tal maneira lavrada que sendo obra de peças e pedra mole que mais direita nem melhor lavrada, nem de mais lavores se não possa fazer. Serão estes arcos de fora mais de duas lanças de altura. Não há em toda esta roca em que está a igreja uma só diferença, toda parece um só mármore. O campo ou crasta que tem esta igreja derredor, todo lavrado na mesma pedra é de sessenta palmos de ancho, para cada cabo, e de fronte da porta principal é de cem palmos. Sobre esta igreja, onde havia de ser telhado, estão por bandas nove arcos grandes, como crastas, deitados que descem de cima por baixo às sepulturas, pelas bandas, como as da outra igreja. A entrada desta igreja é por baixo da mesma roca oitenta passos lavrados na pedra artificialmente, em largueza que poderão ir dez homens por mãos, e alto, altura de uma lança ou mais. Tem esta serventia quatro furos para cima que dão vista no caminho por cima das bordas.» ${ }^{39}$

Vejamos a planta ${ }^{40} \mathrm{em}$ pormenor:

A - Capelas, com o altar-mor, tecto e quatro colunas (P 135: «A capela-mor é muito alta e mui alta a charola sobre o altar com um esteio em cada quadra»).

B - Abóbada.

C - Sete colunas (P 134: «em cada uma [nave] sete colunas de quadra»).

D - Porta principal (P 135: 9x4,5 palmos).

E - Sete colunas com meio círculo formando meia-lua (P 135: «Da parte de fora desta igreja estão sete esteios com lunas»).

$\mathrm{F}$ - O circuito - «umgang» (P 135: «O campo ou crasta que tem esta igreja derredor... é de sessenta palmos de ancho, para cada cabo, e de fronte da porta principal é de cem palmos»).

$\mathrm{G}$ - Entrada sob a roca.

$\mathrm{H}$ - Buraco por onde cai a luz (P 136: «Tem esta serventia quatro furos para cima que dão vista no caminho»).

I - Sepulturas.

$\mathrm{K}$ - Grandeza e medida do palmo.

38 P. Francisco Álvares, Wahrhaftiger Bericht, p. 199: «jedes fach (hat) gevierte seulen / die haben vier palmen in vierung / und stethn von der mauren sechs palmen weit.»

39 P. Francisco Álvares, Verdadeira informação, LV, 135-136.

40 Gravura p. 176. 


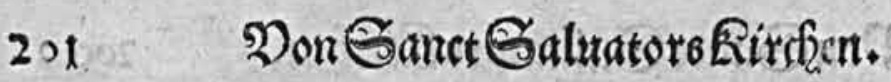

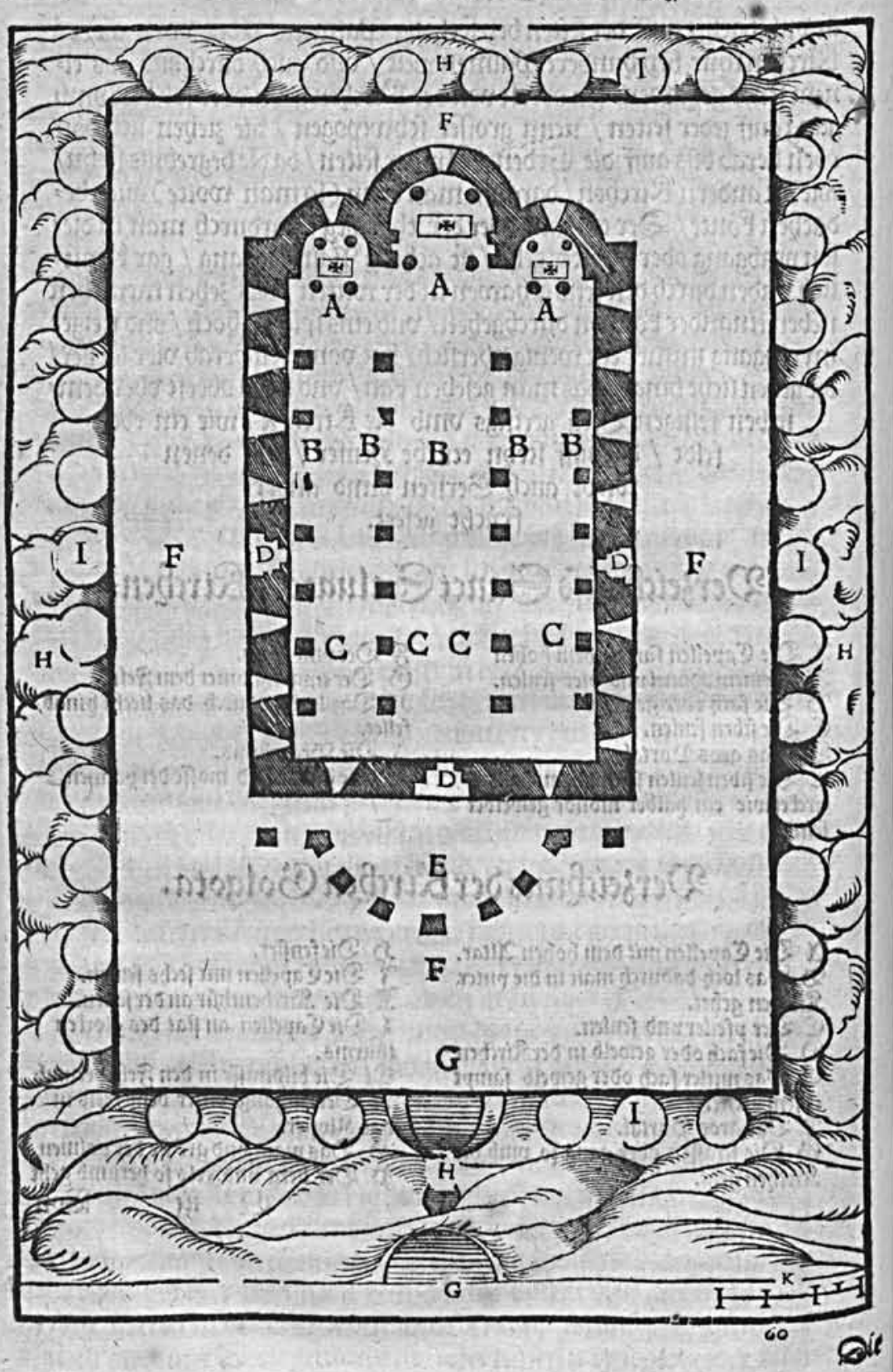


Traduziram-se para a planta um grande número de elementos. As dimensões da igreja $\left(10^{\mathrm{cm}} \times 5,3^{\mathrm{cm}}\right.$ no interior) aproximam-se da proporção (largura $3 / 5$ do comprimento). Mas aplicar a medida do palmo $\left(0,8^{\mathrm{cm}}\right)$ obrigaria a uma planta de $1,60^{\mathrm{m}}$. De resto, há pouco a censurar. As cinco naves, as fiadas de sete colunas, a porta principal, as sete colunas da parte de fora, o «campo ou crasta que tem esta igreja derredor», as sepulturas e a entrada sob a roca, até as clarabóias («furos») que iluminam o corredor subterrâneo... tudo está lá. Nada indica, porém, que as sete colunas exteriores estejam dispostas em semicírculo ou «meia-lua» («ein halber monde»). Pelo contrário, o original diz que as «lunas» estão igualmente afastadas (12 palmos) da parede da igreja. O tradutor entendeu erradamente «lunas» (lunetas que embelezavam as colunas) por meias luas.

A igreja de Santa Maria passa a designar-se por «casa ou igreja de Nossa Senhora»; «não é tão grande como a do Salvador, mas é muito bem obrada.» As dimensões ( 80 x 64 palmos) vêm no fim da descrição. O que o templo perde em tamanho ganha em perfeição: «Tem três naves e a do meio muito alta com grandes laços e rosas na mesma roca lavradas muito subtilmente.

Tem em cada nave cinco colunas e sobre elas seus cercos e abóbadas mui revindas e mui bem feitas. Tem mais uma coluna mui alta no cruzeiro sobre que se afirma uma charola que parece em sua laçaria que foi imprimida em cera. Tem na cabeça de cada nave uma capela com seu altar, assim como as do Salvador. Somente tem mais estas em cada uma das portas que são do tamanho e da feição das do Salvador. Tem seis esteios da parte de fora, os dois de cada parte estão como apegados na parede e os quatro afastados e de uns para outros mui bem feitos arcos e sobre eles mui bem feitas charolas muito altas, que ficam como alpendres, sobre as portas. São estas charolas todas de um compasso, tanto largas como anchas, seja quinze palmos de comprido e outros tantos de ancho. Tem muito alto e gentil circuito, assim detrás como das bandas e diante na roca derredor toda da altura da igreja. Esta igreja é de comprido oitenta palmos e de largo sessenta e quatro.» ${ }^{41}$

Notável na perfeição da obra escultórica de abóbadas e arcos, a igreja da Nossa Senhora distingue-se ainda pelo harmonioso conjunto arquitectónico em que se insere. Em frente, ergue-se uma casa de acolhimento aos peregrinos pobres:

$41 \quad$ Ibid., 136. 
«Tem mais esta igreja defronte à porta principal, na mesma roca grande, casa em que dão de comer a pobres. E para esta casa sai a serventia da igreja para fora ou por ela entram à igreja por baixo da própria roca mui gram peça». ${ }^{42}$

Dos lados, estão duas igrejas mais pequenas: «e de cada parte desta igreja, em frente das portas travessas estão duas igrejas cada uma de seu cabo. (...) ... e a igreja que está para a parte da Epístola é de comprido [sessenta e quatro palmos e de largo trinta e oito]. ${ }^{43}$ Tem três naves e em cada nave três colunas mui bem obradas e de obra chã, não tem mais que uma capela e um altar feito como [a outra igreja]. ${ }^{44}$ Tem a porta principal mui bem obrada, não tem rosto diante senão corredor por baixo da roca que vem como caminho para a casa de Nossa Senhora. Este corredor vem de mui longe, onde começa sobem a ele quinze degraus da mesma roca, esta é mui escura serventia. Para a parte da igreja de Nossa Senhora tem esta igreja mui gentil porta travessa e duas mui galantes frestas e para trás e para a outra parte tudo roca talhada e mui brava sem haver aí obra nenhuma.»

Esta igreja se chama dos Mártires e a igreja que está para a parte do Evangelho do circuito de Nossa Senhora se chama Santa Cruz, é pequena, tem de comprido sessenta e [quatro] palmos [e de largo trinta e] oito, ${ }^{45}$ não tem naves, tem três colunas, pelo meio, que parece que têm o cume para cima, muito bem feita, abobadada e tudo é por dentro obra chã. Para a parte da igreja de Nossa Senhora tem muito louçã porta travessa e duas frestas mui bem obradas, tem um só altar, como outras, tem a porta principal bem obrada, não tem patim, nem rossio diante, somente corredor como caminho que sai para fora, por baixo da roca, mui longe e mui escuro.» ${ }^{46}$

A versão alemã e a respectiva planta ${ }^{47}$ contemplam o conjunto arquitectónico: igreja principal, duas igrejas laterais e casa de acolhimento e apoio a peregrinos pobres. Mas é original nas medidas das duas igrejas

42 Ibid., 136-137.

43 Texto corrigido de acordo com a versão alemã. P: «é de comprido e de largo como a de Nossa Senhora.»O que além de ser completamente inverosímil, se coaduna mal com as «três naves», ao contrário das cinco da igreja de Nossa Senhora.

44 P: «como as outras igrejas».

$45 \mathrm{P}$ : «de comprido sessenta e oito palmos»; falta a largura, ao contrário do habitual. Foi erro mecânico, originado por se saltar dos «sessenta» palmos de comprimento para a última cifra (dos «trinta e) oito» da largura. O tradutor alemão não ia inventar as dimensões da largura.

46 Ibid., 136-137.
47 Gravura p. 180. 
mais pequenas e em pormenores da casa de acolhimento. Indica as medidas, que julgo correctas, das duas igrejas: 64 x 38 palmos. Essas medidas perderam-se no original português. As medidas da igreja «da direita» (assim traduzindo correctamente «do lado da Epístola», expressão que a última reforma litúrgica obnubilará em breve) perderam-se no original português, que tem uma história textual complexa, dando um incompreensível «é de comprido e de largo como a de Nossa Senhora.» Da igreja da esquerda («que está para a parte do Evangelho») sobrou o comprimento de «sessenta e oito palmos», lectio conflata de «de comprido sessenta e quatro palmos e de largura trinta e oito ».

$\mathrm{O}$ albergue de acolhimento e apoio teria «cinco divisões» («fünff wohnungen») e um «pórtico ou entrada coberta com duas colunas» (mit einem portico oder bedeckten gang mit zweyen seulen». ${ }^{48}$

A planta é fiel aos quatro edifícios e até às três colunas de uma das capelas. Só com a manifesta troca das igrejas mais pequenas. A igreja da direita é que tem «três naves e em cada nave três colunas», não a que se apresenta na planta à esquerda.

A - As capelas (P: «na cabeça de cada nave uma capela com seu altar»).

B - A coluna com o céu (himel; P: «uma coluna mui alta no cruzeiro», com «charola»).

C - As naves e abóbadas.

$\mathrm{D}$ - As colunas (P: «em cada nave cinco colunas»).

E - As três portas grandes («portas que são tamanhas e da feição das do Salvador»).

$\mathrm{F}$ - O pórtico exterior ou abóbada com as colunas e um «céu» (P: «seis esteios da parte de fora, os dois de cada parte estão como apegados à parede... e sobre eles mui bem feitas charolas».

$\mathrm{G}-\mathrm{O}$ circuito (P: «Tem muito alto e gentil circuito»).

$\mathrm{H}$ - Abrigo dos pobres (P: «casa em que dão de comer aos pobres»).

I - A escada em que se pode andar debaixo da roca (P: «corredor» a que «sobem» «quinze degraus da mesma roca»).

$\mathrm{K}-$ as duas colunas da casa (dos pobres), omissas em $\mathrm{P}$.

L - Pórtico ou abóbada (A: «casa grande com cinco divisões e um pórtico de duas colunas»), omisso em P.

M - Quatro diferentes átrios (? - vorheng), omissos em P.

$\mathrm{N}$ - A igreja dos Mártires (colocada erradamente à esquerda).

$\mathrm{O}$ - A igreja de Santa Cruz (colocada erradamente à direita).

$\mathrm{P}$ - As portas travessas (da igreja de Nossa Senhora).

$\mathrm{Q}$ - A passagem sob a rocha ( $\mathrm{P}$ : «este corredor vem de mui longe»).

$\mathrm{R}-\mathrm{A}$ entrada sob a rocha.

$\mathrm{S}$ - Roca circundante.

$\mathrm{T}$ - Medida do palmo.

V - As janelas (P 127: «mui galantes frestas»).

48 P. Francisco Álvares, Wahrhaftiger Bericht, 202. 


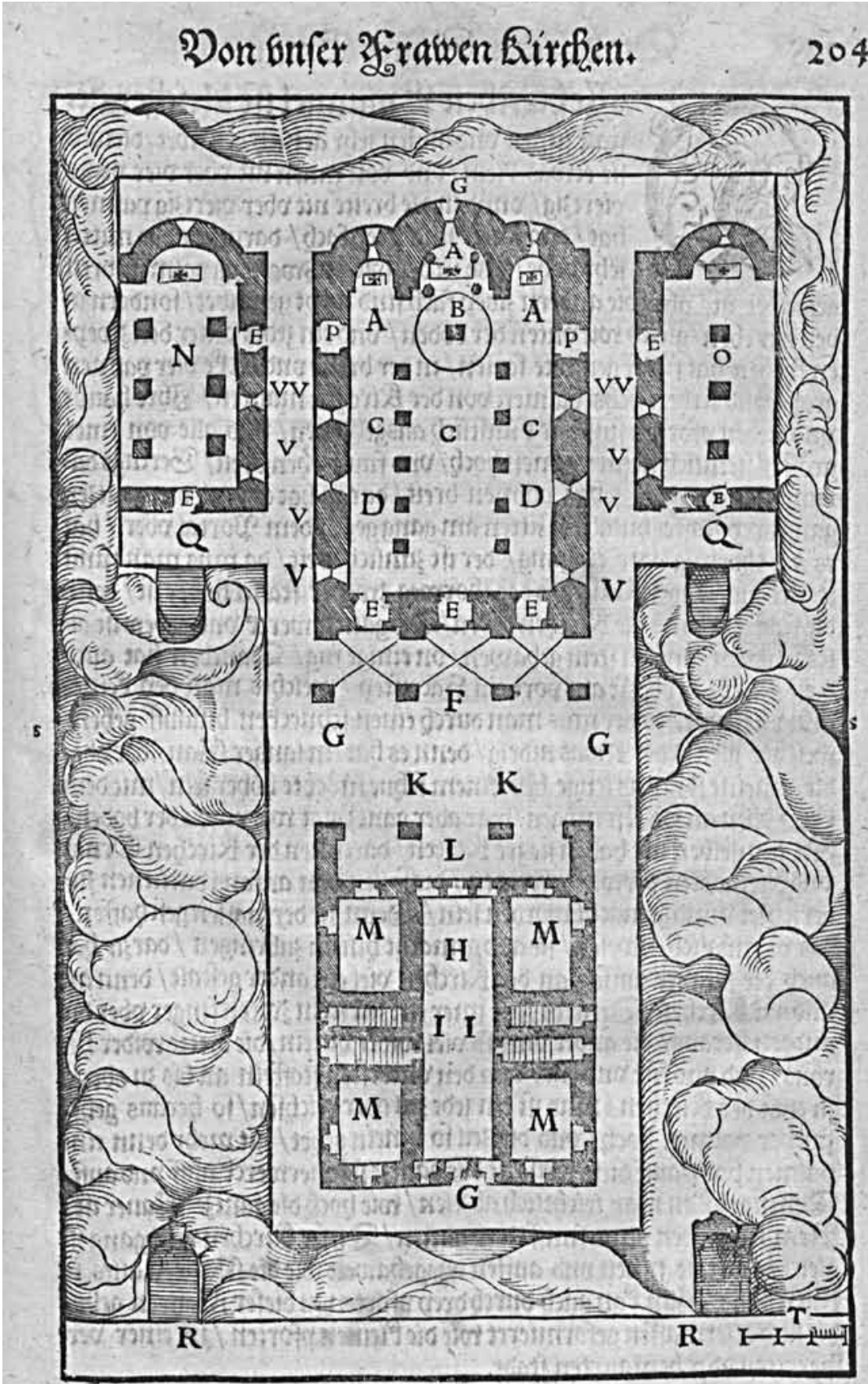


A igreja de Emanuel, embora pequena (42 x 20 palmos), era das mais trabalhadas, nas palavras do cronista «mui obrada assim de dentro como de fora». «Tem três naves, a do meio é muito alta e muito revinda, abobdada, as naves das bandas não são abobadadas e são chãs por baixo, seja o céu delas assim como o andar da igreja. Estas naves estão sobre cinco esteios, a largura ou grossura destes esteios são de quatro palmos de quadra a quadra e outros quatro tem a parede da igreja. Tem muito bem lavradas portas, assim a travessa, como a principal e todas de um tamanho, seja nove palmos em alto e quatro em largo.»

$\mathrm{O}$ exterior do templo tinha um arranjo peculiar - não propriamente o circuito, que todas tinham, mas os degraus, a feição das paredes e o muro cavado na rocha: «É toda cercada, da parte de fora curral, de três degraus que a cercam derredor, salvo as portas que tem cada uma seu patim largo, em cada um cinco degraus sobre os que cercam a igreja, toda é da mesma roca sem peça nem falha.» Depois da intromissão do coro, continua como surpreso: «Têm mais as paredes de fora desta igreja o que não têm as outras, seja como fiadas de paredes, e uma sai para fora e outra entra para dentro dois dedos e outra torna a sair e outra a entrar, e assim são dês o começo dois degraus até cima da igreja e a fiada da pedra que sai é de dois palmos de largo e a que entra é de um e desta maneira e largueza correm toda a parede e lançando conta dos palmos, esta altura é de cinquenta e dois palmos.»

«Tem a igreja todo seu circuito como muro talhado de dentro e de fora da mesma roca e entra-se a este muro por mui boas três portas, como portas pequenas de cidade ou vila cercada.» Mesmo com a fraca luminosidade ambiente, devia ser grato contemplar tais paredes, compostas de fiadas intermitentes de saliências e reentrâncias. O coro era outra nota distintiva da igreja de Emanuel: «Tem mais esta igreja o que não tem outra nenhuma, seja, coro, ao qual sobem por escada de caracol e não é muito porque um homem alto e grande com mais um palmo dará em cima com a cabeça e por cima chão como o andar da igreja e assim sobre as naves e bandas tamanho como elas são, tanto vão em casinhas e portas de uma para outra e do mesmo coro vão portas para estas casinhas ou celas. Não se servem deste coro senão de caixas de roupas e ornamentos da igreja. Estas caixas deviam ser feitas dentro neste coro, porque não podiam entrar por nenhuma parte a ele ainda em peças não sei como entraram.» ${ }^{49}$

49 P. Francisco Álvares, Verdadeira informação, LV, 137-138. 
Também não sei que mais admirar - se o olho de arquitecto, se a precisão de engenheiro. $\mathrm{O}$ olho de arquitecto deleita-se nas fiadas intermitentes de saliências e reentrâncias, na «escada de caracol» do coro, nos degraus a quebrar a monotonia do espaço envolvente, no muro protector com portas, «como portas pequenas de cidade ou vila cercada». Com precisão de engenheiro, indicam-se as medidas da saliência e reentrância (dois dedos), bem como a largura horizontal das fiadas (dois palmos na que sai e um palmo na que entra) e a altura total da parede (cinquenta e dois palmos); no coro, as dimensões das caixas indicavam que tinham sido feitas lá dentro, porque não cabiam nas portas e «ainda em peças não sei como entraram».

O tradutor alemão entendeu bem e esforçou-se por exprimir quase tudo em planta. ${ }^{50}$ A excepção é o coro. Levado pelo mobiliário, pensou tratar-se da sacristia, e colocou-a no topo exterior da igreja. Numa igreja portuguesa, que servia de referência a Francisco Álvares, o coro elevava-se no interior da igreja logo após a entrada principal, e não de fora. A diferença era que não servia para assistir à missa, mas para arrecadação, e prolongava-se por «casinhas» como sótão da igreja.

Há ainda uma anomalia nas dimensões das portas e duas indicações omissas no original português. Segundo este, as portas eram compreensivelmente mais altas ( 9 palmos) que largas (4 palmos). A tradução dá a mesma altura e uma largura (impossível?) de quinze palmos («fünffzehen breit»). A mais, indica-se a distância (seis palmos) das colunas às paredes: («sechs palmen von der kirchen mauern») e uma passagem de dez palmos de largura à volta da igreja («Verings darumb ist ein gang zehen palmen breit»), donde descem os três degraus. ${ }^{51}$

Oferecem-se duas plantas, uma para o plano do interior, outra para a parede exterior em altura.

I

A - As três naves.

$\mathrm{B}-\mathrm{O}$ altar-mor.

$\mathrm{C}-\mathrm{As}$ colunas ou pilares (P: «cinco esteios quadrados de quatro palmos»).

$\mathrm{D}$ - As portas (P: «mui lavradas portas, assim a travessa como a principal», porta «travessa» no singular, de que o alemão fez duas).

$\mathrm{F}-\mathrm{A}$ escada ou degraus comuns.

$\mathrm{G}-\mathrm{O}$ circuito.

$\mathrm{H}$ - As três portas exteriores do circuito (as portas deviam ser do muro, que falta nesta planta).

I - A roca circundante.

50 Gravura p. 183-184.

51 P. Francisco Álvares, Wahrhaftiger Bericht, 205. 


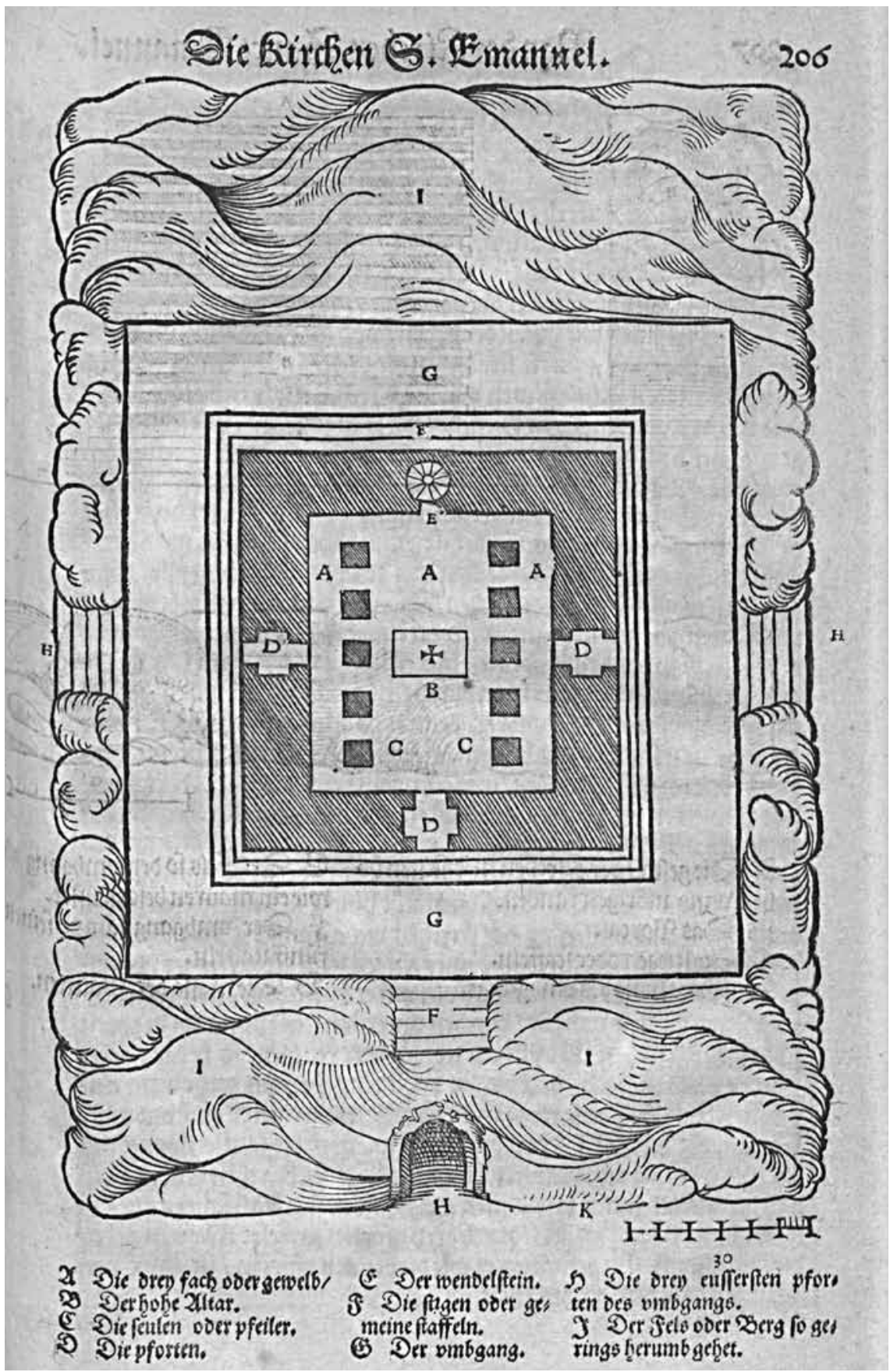


II

A - A forma da parede com as suas fiadas salientes e reentrantes.

$\mathrm{B}-\mathrm{O}$ pórtico.

$\mathrm{C}-\mathrm{A}$ escada ou degraus.

$\mathrm{D}$ - O lugar do circuito.

E - A rocha assim o circuito fechado como um muro.

$\mathrm{F}-\mathrm{O}$ circuito com os seus cinco degraus. (P: «cinco degraus sobre os que cercam a igreja», só no acesso às portas).

$\mathrm{G}-\mathrm{A}$ medida do palmo.

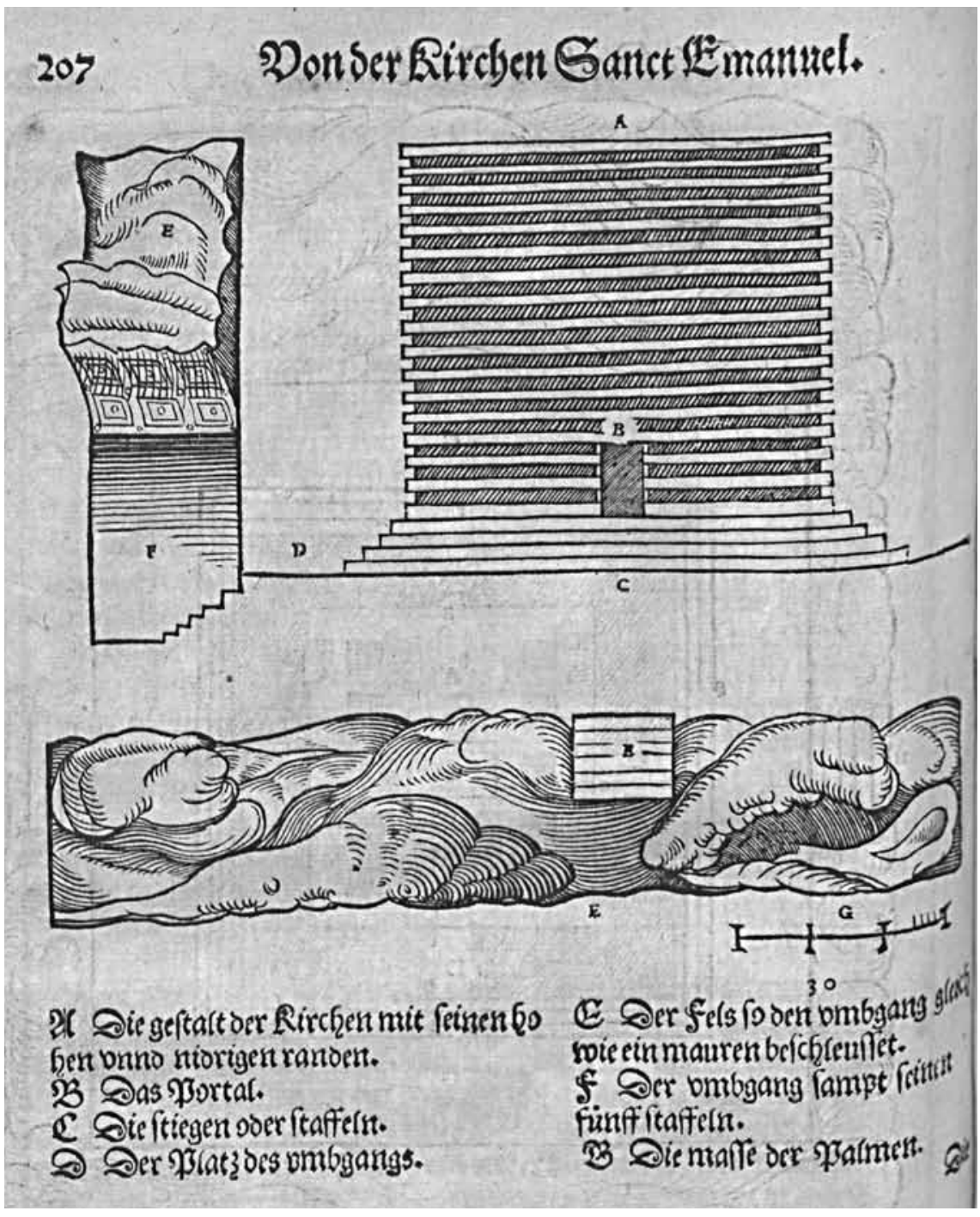


A igreja de São Jorge é a que menos espaço ocupa, pela simples razão de o capelão-cronista não ter lá entrado: «mui bem lavrada das portas de fora, que dentro não entrei por estar fechada.» Quanto a estar «apartada da roca» e a ter sepulturas no circuito, era igual às demais. Mas o espaço exterior tinha particularidades de sobra para a igreja não ser ignorada.

«A igreja de São Jorge está um grande pedaço abaixo das outras quase como apartada do lugar em roca como as outras, a entrada por que se entra a ela é por baixo da roca ou fraga, são oito degraus de subir e subidos estes degraus entram em uma casa boa e grande com um poial que a cerca toda derredor, da parte de dentro, que, de fora, é roca brava, nesta casa se dão esmola (sic) aos pobres e assenta-se nos poiais. Entrando desta casa para dentro é logo circuito da igreja que é feito em cruz e assim é feita a igreja em cruz e tanto é da porta principal à ousia, como de uma porta travessa a outra, tudo de um compasso e mui lavrada das portas de fora, que dentro não entrei por estar fechada. No circuito da igreja, entrando de fora para a mão direita que tudo é roca brava sem ter mais de uma entrada, está na altura de um homem pouco mais, metida na mesma parede, como arca cheia de água, e, sobem a ela por degraus, e, dizem nascer aí aquela água, mas ela não corre, levam-na para as maleitas e dizem que lhe presta. Todo este circuito é cheio de sepulturas como as outras igrejas. Por cima desta igreja tamanha, está uma cruz dobrada, seja uma dentro em outra, como as cruzes da ordem de Cristo.» ${ }^{52}$

O tradutor alemão simplificou uma expressão ou outra, entendeu «tudo de um compasso» como «com grande diligência» («mit grossem vleis»), verteu «maleitas» por «febre» («Fieber») e acrescentou «ou menos»a «na altura de um homem pouco mais», que pode corresponder à letra ou ao espírito original («pouco mais ou menos», «ungefehrlich eins Mans höhe»). Nada que desvirtuasse o sentido fundamental do texto. A planta do complexo dá uma preciosa ajuda à visualização do espaço. Aí estão «a entrada... por baixo da roca», a «casa boa e grande», os circuitos (da igreja e da casa), a igreja em cruz grega com portas e frestas (estas omissas no texto), as sepulturas. Só não se entende a designação da capela-mor por «igreja da Santa Cruz» (A) nem a colocação do altar no centro. Até a versão de «ousia» por «altar-mor» («von dem grossen Portal zum hohen Altar») supõe que este se encontrava para o fim do eixo vertical que vinha do pórtico. ${ }^{53}$

52 P. Francisco Álvares, Verdadeira informação, LV, 139.

53 Gravura p. 186. 


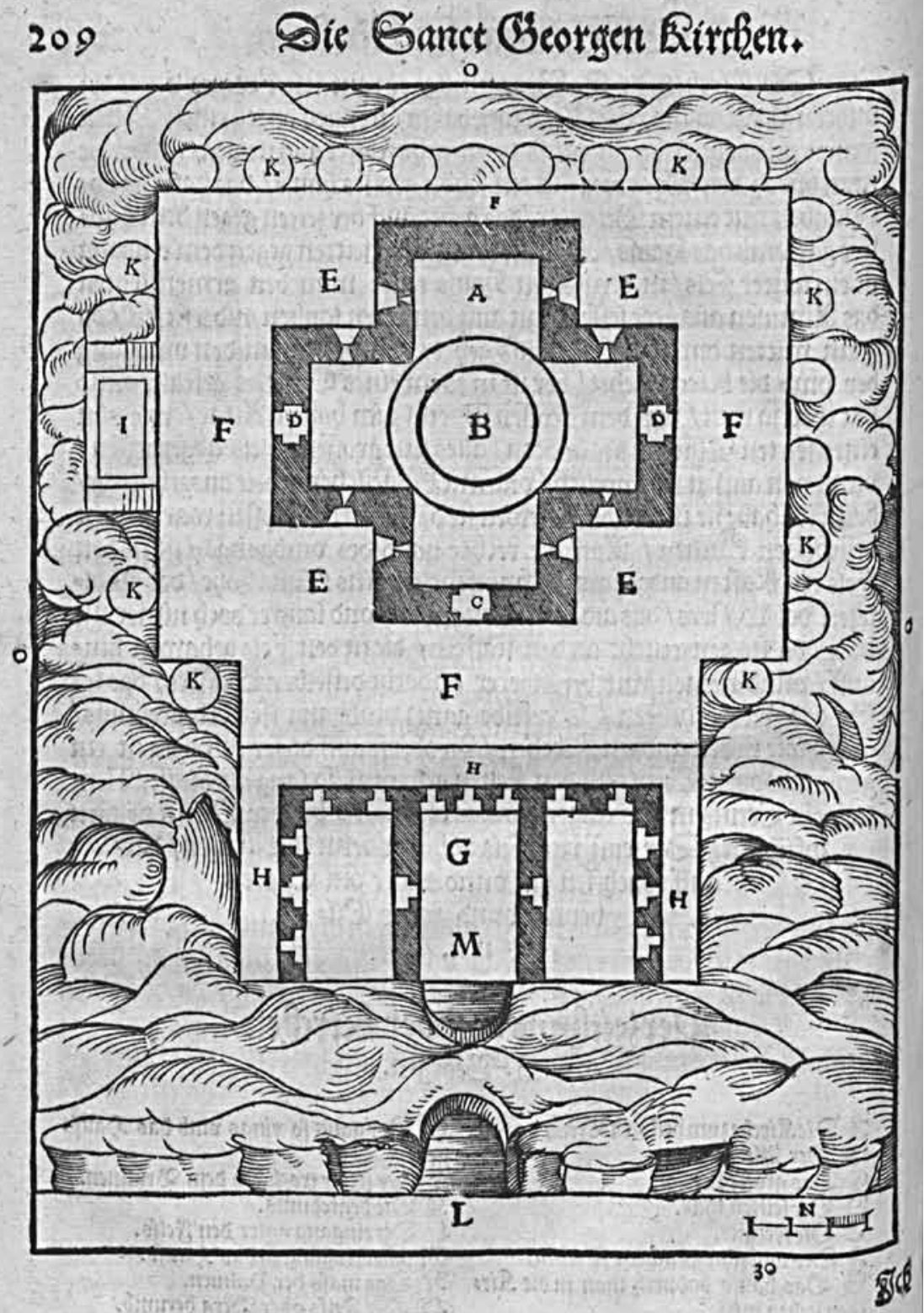




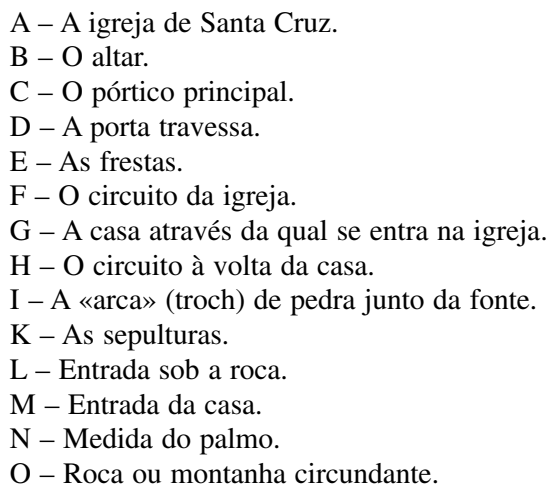

O tradutor germânico não se contentou com original português e compulsou-o com a versão italiana de Ramusio e com um manuscrito de Damião de Góis que dela divergia «em muitos lugares». É o que se depreende do longo prefácio. ${ }^{54} \mathrm{~A}$ versão italiana era notoriamente mais curta que a edição de Lisboa. ${ }^{55}$ Ao invés, o tradutor alemão notou grandes lacunas no original português e procurou melhorá-las com base no manuscrito. ${ }^{56}$ É o que acontece na descrição das igrejas de Lalibela.

As plantas das igrejas são uma novidade absoluta da edição germânica, acrescentando um suplemento de clareza e conforto para o leitor; ao contrário da tradução espanhola de 1557 , que nem sequer respeitou a divisão em capítulos e tornou o texto mais denso. Depois das versões em italiano, espanhol e francês, a tradução alemã não só ampliou o horizonte

54 «Vorrede vnd Bericht / wie vnd aus was Vrsachen des Priester Johans Königreich in Ethiopien / Erstlichen erkündiget vnd an den tag gebracht worden.»

55 De acordo com a investigação de R. Almagià, Contributi alla storia della conoscenza dell'Etiopia, Padova 1941, as diferenças entre uma e outra devem-se tanto à vontade de abreviar como ao facto de o italiano depender de duas fontes. As divergências de estrutura entre P e A (seriação unitária dos capítulos, sem I e II Parte) coincidem, e portanto dependem da edição italiana de Ramusio.

56 A edição de Lisboa continha numerosas faltas de texto, com prejuízo para a compreensão da matéria («in dem Portugalesischen druck /... offt hin vnd wider gantze zeile ausgelassen / also das man in viel vornemen stücken / zu keinem rechten verstand komen könte», «Vorrede», sem numeração de páginas). Cf. J. Nunes Carreira, «Da Verdadera Informaçam ao Wahrhaftiger Bericht. As recensões e a versão alemã de um relato de viagem», Runa. Revista portuguesa de estudos germanísticos 13-14 (número especial de Homenagem ao Professor Dr. Olívio Caeiro), 1990, 157-169 
cultural da Verdadeira Informação, como também, introduzindo plantas das igrejas e do espaço envolvente, deu igualmente um inestimável contributo à compreensão e admiração do complexo arquitectónico de Lalibela. As plantas, se não remontam ao manuscrito de Francisco Alvares, que só ele vira igrejas de Lalibela, devem-se ao tradutor/editor alemão, que, aliando capacidade técnica e fantasia, as desenhou ou mandou desenhar a partir da descrição do cronista.

O Padre Francisco Álvares foi o primeiro europeu, e não só o primeiro português, a ver e descrever as igrejas de Lalibela. 